\title{
Vacuolar sequestration capacity and long-distance metal transport in plants
}

\author{
Jia-Shi Peng ${ }^{1,2}$ and Ji-Ming Gong ${ }^{1,2}$ * \\ ' National Key Laboratory of Plant Molecular Genetics, Institute of Plant Physiology and Ecology, Shanghai Institutes for Biological Sciences, \\ Chinese Academy of Sciences, Shanghai, China \\ ${ }^{2}$ National Center for Gene Research, Institute of Plant Physiology and Ecology, Shanghai Institutes for Biological Sciences, \\ Chinese Academy of Sciences, Shanghai, China
}

\author{
Edited by: \\ Felipe Klein Ricachenevsky, \\ Universidade Federal do Rio Grande \\ do Sul, Brazil \\ Reviewed by: \\ Ryoung Shin, Riken Plant Science \\ Center, Japan \\ Tetsuro Mimura, Kobe University, \\ Japan \\ *Correspondence: \\ Ji-Ming Gong, National Key \\ Laboratory of Plant Molecular \\ Genetics and National Center for \\ Gene Research, Institute of Plant \\ Physiology and Ecology, Shanghai \\ Institutes for Biological Sciences, \\ Chinese Academy of Sciences, 300 \\ Fenglin Road, Shanghai 200032, \\ China \\ e-mail: jmgong@sibs.ac.cn
}

The vacuole is a pivotal organelle functioning in storage of metabolites, mineral nutrients, and toxicants in higher plants. Accumulating evidence indicates that in addition to its storage role, the vacuole contributes essentially to long-distance transport of metals, through the modulation of Vacuolar sequestration capacity (VSC) which is shown to be primarily controlled by cytosolic metal chelators and tonoplast-localized transporters, or the interaction between them. Plants adapt to their environments by dynamic regulation of VSC for specific metals and hence targeting metals to specific tissues. Study of VSC provides not only a new angle to understand the long-distance root-to-shoot transport of minerals in plants, but also an efficient way to biofortify essential mineral nutrients or to phytoremediate non-essential metal pollution. The current review will focus on the most recent proceedings on the interaction mechanisms between VSC regulation and long-distance metal transport.

Keywords: vacuolar sequestration capacity, vacuole, transporter, chelator, metal transport

\section{INTRODUCTION}

Mineral nutrients including iron $(\mathrm{Fe})$, zinc $(\mathrm{Zn})$, copper $(\mathrm{Cu})$, manganese $(\mathrm{Mn})$, nickel $(\mathrm{Ni})$, and molybdenum $(\mathrm{Mo})$ are required in different amounts by different plant tissues. Therefore, once taken up into plants, long-distance transport and allocation of these metals play a pivotal role in plant development and adaptation to the environment. To date, studies of long-distance root-to-shoot metal transport within plants focus preferentially on transporters localized to either xylem parenchyma cells or phloem companion cells, as they directly mediate xylem and phloem loading or unloading thus contributing essentially to this metal reallocation process. Moreover, some chelators, including nicotianamine (NA; reviewed by Curie et al., 2009), glutathione (GSH), and phytochelatins (PCs; reviewed by Mendoza-Cozatl et al., 2011), were observed to also act as important players in the process of long-distance transport of metals.

Plant vacuoles are predominant organelles serving as temporary storages for essential and toxic metabolites, mineral nutrients and toxic pollutants. Accumulating evidences indicate that in addition to the direct regulation from those ion transporters and chelators, the Vacuole sequestration capacity (VSC) also contributes substantially to long-distance transport and allocation of metals in plants. Vacuoles function as buffering pools where the sequestration capacities are dynamically adjusted to the changing environmental cues, through the interaction between tonoplast-localized transporters and ion chelators. This mini-review will focus on the regulation of VSC and its interaction with long-distance root-to-shoot transport of either essential or non-essential metals in plants.

\section{REGULATION OF VSC REGULATION BY TRANSPORTERS}

Up to date, most tonoplast-localized metal transporters in plants (reviewed by Martinoia et al., 2012) have been identified to regulate VSC and hence metal allocation between different organs or tissues (Table 1).

In response to mineral nutrient deficiency, genes involving in nutrient remobilization from vacuoles to cytosols, such as NRAMP3 and NRAMP4 (Thomine et al., 2000, 2003), are up-regulated, thus reducing the VSC to release the stored nutrients and consequently alleviating nutrient deficiency. In contrast, other genes including MTP3 (Metal Transporter 3; Arrivault et al., 2006), ZIF1 (Zinc-Induced Facilitator 1; Haydon and Cobbett, 2007), VIT2 (Vacuolar Iron Transporter 2; Zhang et al., 2012), CAX4 (Cation Exchanger 4; Mei et al., 2009), which regulate metal sequestration into vacuoles, are up-regulated when excessive metals are available in the environment, and the enhanced expression consequently leads to enlarge VSC and metal accumulation in vacuoles. Another group of genes including VIT1(Kim et al., 2006; Zhang et al., 2012), MTP1 (Kobae et al., 2004; Desbrosses-Fonrouge et al., 2005; Kawachi et al., 2009), COPT5 (Copper Transporters 5; GarciaMolina et al., 2011; Klaumann et al., 2011), remain unaffected by the metal status in the environment, though functional abortion 


\begin{tabular}{|c|c|c|}
\hline Transporters & Mineral & Reference \\
\hline MTP1 & $\mathrm{Zn}$ & reviewed by Ricachenevsky etal. (2013 \\
\hline MTP3 & $\mathrm{Zn}$ & Arrivault et al. (2006) \\
\hline ZIF1 & $\mathrm{Zn}$ & $\begin{array}{l}\text { Haydon and Cobbett (2007), Haydon } \\
\text { etal. (2012) }\end{array}$ \\
\hline NRAMP3/NRAMP4 & $\mathrm{Fe}$ & $\begin{array}{l}\text { Thomine et al. (2003), Lanquar et al. } \\
\text { (2005) }\end{array}$ \\
\hline VIT1NIT2 & $\mathrm{Fe}, \mathrm{Zn}$ & Kim et al. (2006), Zhang etal. (2012) \\
\hline FPN2(IREG2) & $\mathrm{Fe}, \mathrm{Co}, \mathrm{Ni}$ & $\begin{array}{l}\text { Morrissey etal. (2009), Schaaf etal. } \\
\text { (2006) }\end{array}$ \\
\hline COPT5 & $\mathrm{Cu}$ & Klaumann etal. (2011) \\
\hline CAX2/CAX4 & $\mathrm{Cd}$ & Korenkov et al. (2007) \\
\hline HMA3 & $\mathrm{Cd}$ & Ueno et al. $(2010,2011)$ \\
\hline
\end{tabular}

of these genes altered metal allocation at either subcellular or tissue levels, suggesting that a stable expression level of those genes enables proper metal allocation.

Metal hyperaccumulators modulate their VSC via a more conservative way than we have imagined, as they tend to utilize some transporters which are also present in their corresponding non-hyperaccumulators but have evolved with more complex regulation mechanisms. MTP1 is a key transporter modulating the VSC of Zn (Sinclair and Krämer, 2012; Ricachenevsky et al., 2013). Piled evidences suggest that the expression level of MTP1 is greatly enhanced in various metal hyperaccumulators (Assunção et al., 2001; Persans et al., 2001; Becher et al., 2004; Dräger et al., 2004; Hammond etal., 2006; Talke etal., 2006; van de Mortel et al., 2006; Gustin et al., 2009; Shahzad et al., 2010; Zhang et al., 2011), which later on was shown to be attributable to genome amplification of gene copies, in contrast to a single copy in their relative non-hyperaccumulators (Dräger et al., 2004; Shahzad et al., 2010). A similar regulation of TcHMA3 (Heavy Metal ATPases 3) was also observed (Ueno et al., 2011), among which gene amplification leads to much higher expression of TcHMA3 in the accumulating ecotype Ganges of Thlaspi caerulescens than in the non-accumulating Prayon, thus VSC of Cd in roots is greatly reduced and more metal is driven to translocate to shoots.

\section{REGULATION BY CHELATORS}

Phytochelatins are important chelating molecules in plants, which detoxify heavy metals via chelation and hence forming stable PCsmetal complexes which are subsequently sequestered into vacuoles (Cobbett and Goldsbrough, 2002). In an effort to identify the relative contribution to VSC by PCs and GSH, the authors unexpected found that when ectopically expressing $S p H M T 1$, a fission yeast gene encoding vacuolar PC-Cd transporters, the rate of long-distance Cd transport was significantly delayed in Arabidopsis (Huang et al., 2012). They assumed that this delay might be due to the enlarged VSC in root vacuoles. To test their hypothesis, SpHMT1 was targeted to roots and as expected, accumulation of
$\mathrm{Cd}, \mathrm{Cu}$, and $\mathrm{As}$ in seeds was reduced up to $70 \%$ of the controls. These results show that VSC of heavy metals is essentially regulated by PCs.

Nicotianamine is another kind of metal chelator which is ubiquitously present in higher plants. Recent studies suggest that NA modulates the VSC of $\mathrm{Zn}$ and $\mathrm{Fe}$ and hence their distribution. In the hyperaccumulator Arabidopsis halleri, large amounts of NA is present in the root tissues and was proposed to essentially contribute to long-distance transport of $\mathrm{Zn}$ to shoots, as in the AhNAS2-RNAi plants with substantially reduced NA contents, much less $\mathrm{Zn}$ was observed in the xylem sap and shoots (Deinlein et al., 2012). Another research showed that overexpression of AtZIF1 in Arabidopsis enhanced NA sequestration into vacuoles (Haydon etal., 2012), which consequently led to Fe overaccumulation in shoot tissues. The authors implicated that enhanced vacuolar NA sequestration depleted cytosolic NA, thus affected the intercellular mobility of $\mathrm{Fe}$ as Fe-NA complex (Haydon et al., 2012).

The amino acid histidine (His) was also identified to be functional in Ni detoxification and translocation in some Ni hyperaccumulators (Krämer etal., 1996; Kerkeb and Krämer, 2003; Krämer, 2010). Using a tonoplast transport assay strategy, Richau et al. (2009) found that when Ni was supplied as a Ni-His complex, a much higher uptake rate was observed in tonoplast vesicles derived from the hyperaccumulator than those from the nonhyperaccumulator T. arvense. Given high concentration of His was mainly found in T. caerulescens roots, and the level is about 10 times of that in T. arvense roots, they postulated that accumulation of His in T. caerulescens roots reduces the VSC of Ni by cytosolic chelation, thus promoting Ni transport and hyperaccumulation in shoots.

In general, VSC regulation by chelators could be classified into two categories: (1) the chelated metals are prone to translocation into vacuoles, thus enlarging VSC of certain metals; or (2) chelation of metals leads to reduced vacuolar sequestration and hence decreasing the VSC of certain metals. Root-targeted expression of TaPCS1 in cad1-3 significantly enhanced root-to-shoot long-distance transport of Cd (Gong et al., 2003), and disruption of NA biosynthesis retained $\mathrm{Zn}$ in roots (Deinlein et al., 2012). All these studies suggest that chelation of metals by PCs or NA tends to promote long-distance metal transport, though the chelation is supposed to enlarge VSC to some extent. One possible explanation might be that the VSC regulated by chelators is also dependent on relevant transporters, as overexpression of SpHMT1, the PC-Cd complex transporter, successfully trapped $\mathrm{Cd}$ in roots (Huang et al., 2012), indicating a complex interaction between chelators and their transporters in the regulation of VSC.

\section{VSC REGULATES LONG-DISTANCE METAL TRANSPORT IN PLANTS} VSC AND TRANSPORT OF MINERAL NUTRIENTS

Consistent with its major function in photosynthesis, most cellular Fe is found in the chloroplast. However, a substantial amount of this mineral nutrient is also stored in leaf vacuoles. Zhang et al. (2012) isolated two tonoplast-localized metal transporters OsVIT1 and OsVIT2 from rice. Ectopic expression of OsVIT1 and 
OsVIT2 genes partially rescued the Fe and $\mathrm{Zn}$ sensitive phenotypes and increased vacuolar Fe and $\mathrm{Zn}$ accumulation in yeast, suggesting a primary role for OsVIT1 and OsVIT2 is sequestering Fe/Zn into vacuoles across the tonoplast. OsVIT1 and OsVIT2 are highly expressed in rice flag leaves. Functional disruption of these two genes led to decreased Fe/Zn accumulation in flag leaves while enhanced accumulation in rice grains and phloem exudates of flag leaves and uppermost nodes. Meanwhile, no obvious changes were observed in either uptake or root-to-shoot transport of $\mathrm{Fe} / \mathrm{Zn}$ between the mutants and the wild-type. These observations suggest that OsVIT1 and OsVIT2 play an important role in $\mathrm{Fe}$ and $\mathrm{Zn}$ long-distance translocation between source (flag leaves) and sink organs (seeds), via the modulation of VSC for $\mathrm{Fe}$ and $\mathrm{Zn}$ in flag leaves. In Arabidopsis, functional disruption of the tonoplast-localized Fe transporters AtVIT1 (Kim et al., 2006), AtNRAMP3 (Natural Resistance Macrophage Protein 3) and AtNRAMP4 (Lanquar et al., 2005) resulted in growth arrest especially in $\mathrm{Fe}$ deficient condition, providing further support to the hypothesis that modulation of VSC essentially affect Fe mobilization and reallocation between different tissues in plants.

The hypothesis also applies to the modulation of the VSC of $\mathrm{Zn}$ in plants. AtMTP3 mediates $\mathrm{Zn}$ transport into vacuoles and expresses preferentially in Arabidopsis roots. When exposed to excessive Zn, AtMTP3 is induced thus enhancing the VSC and consequently $\mathrm{Zn}$ sequestration into vacuoles in roots. It is believed that this mechanism helps to protect the most important organelles including chloroplasts through reduced long-distance transport of $\mathrm{Zn}$ to aerial tissues (Sinclair and Krämer, 2012). One supportive evidence came from the observation that more $\mathrm{Zn}$ accumulated in shoot tissues of the atmtp3 mutant (Arrivault et al., 2006). Consistent results were obtained in the research of other $\mathrm{Zn}$ transporters such as the tonoplast-localized AtZIF1. AtZIF1 overexpression lines showed decreased $\mathrm{Zn}$ accumulation in shoots and increased root-to-shoot ratios of $\mathrm{Zn}$ concentrations compared to the wildtype control (Haydon and Cobbett, 2007; Haydon et al., 2012), as would be expected according to the theory that $\mathrm{Zn}$ translocation could be mediated by VSC.

Additional supportive evidences came from $\mathrm{Cu}$ reallocation. AtCOPT5 is expressed in root vascular tissues at high levels, and functions as a vacuolar $\mathrm{Cu}$ exporter. In the T-DNA-insertion mutant atcopt5, remarkably increased copper concentrations were observed in the vacuoles compared with those in the wild-type. Correspondingly, more $\mathrm{Cu}$ accumulated in roots and less in siliques and seeds of the mutant plants (Garcia-Molina et al., 2011; Klaumann et al., 2011).

\section{VSC AND TRANSPORT OF TOXIC METALS}

Non-essential toxic metal(loid)s including $\mathrm{Cd}$ and As may lead to adverse effects on plants, mainly through the derived oxidative injuries or competitive inhibition of essential mineral nutrient. To protect the aerial parts which are active in photosynthesis and other important biological processes, plants have evolved sophisticated machineries in regulating metal distribution between roots and shoots, among which VSC also plays a very important role.

One example is about the rice OsHMA3, which has been correlated to $\mathrm{Cd}$ accumulation in rice shoots. Specifically, Ueno etal. (2010) found that a functional disrupted OsHMA3 allele resulted in Cd overaccumulation in rice shoots. Further research revealed that OsHMA3 is localized to the tonoplast in rice roots, and it functions primarily to mediate Cd transport into vacuoles. Overexpression of the functional OsHMA3 allele significantly decreased $\mathrm{Cd}$ accumulation in rice grains, while no apparent effect was observed on the accumulation of other essential micronutrients. These results suggest that the VSC in rice roots mediated by OsHMA3 contributes essentially to the long-distance transport of $\mathrm{Cd}$ from roots to shoots.

Another example is about the metal hyperaccumulators. In contrast to non-hyperaccumulators, hyperaccumulators show extraordinarily high accumulation of toxic metals in aerial parts without any visual effects (reviewed by Krämer, 2010). Interestingly, studies have suggested that VSC regulation also gets involved in both the long-distance transport of toxic metals and the detoxification mechanisms that render plants high tolerance to metals. It was shown that the VSC for $\mathrm{Zn}$ in hyperaccumulator T. caerulescens roots is significantly decreased, compared to the non-hyperaccumulating relative $T$. arvense, which consequently drives more $\mathrm{Zn}$ to translocate from roots to shoots as indicated by the enhanced xylem loading of $\mathrm{Zn}$ in T. caerulescens (Lasat et al., 1998). In different ecotypes of the $T$. caerulescens, it was also found that the efficiency of Cd loading to the xylem is highly correlated to the VSC for Cd in root cells (Xing et al., 2008). A similar correlation between metal translocation efficiency to shoots and its VSC in roots is also found in Sedum alfredii, another $\mathrm{Zn} / \mathrm{Cd}$ hyperaccumulator found specifically in Southern China (Yang et al., 2006). These observations suggest metal transport regulated by VSC modulation might be a common mechanism in hyperaccumulators. In addition to the regulation on long-distance metal transport, VSC also functions on metal detoxification in hyperaccumulators, supportive evidences came from the results that a predominant proportion of shoot $\mathrm{Cd}$ was localized to vacuoles (Küpper et al., 1999, 2001; Krämer et al., 2000; Ma et al., 2005).

\section{CONCLUDING REMARKS AND FUTURE DIRECTIONS}

Vacuoles, occupying over $80 \%$ of the cellular volume in vegetative tissues, are the largest organelles undergoing relatively less metabolisms, which makes it perfect for vacuoles to store chemical compounds and metal ions. However, their role in regulating long-distance root-to-shoot transport of metals has been largely ignored, though such a deduction is becoming more and more apparent with accumulating evidences. Here we proposed that VSC plays a role of "buffering pool" to dynamically mediate long-distance metal transport in plants. Generally the VSC of certain metal varies between different plant tissues to ensure proper metal distribution, e.g., the VSC of toxic metals is larger in roots than in shoots, thus an essential proportion of the toxic metals will be trapped in roots as we normally observe. When exposed to high levels of toxic metals, specifically when the VSC of a certain metal is used up an "overflow" mechanism as proposed (Gong et al., 2003) takes over and the excessive metal is subjected to long-distance root-to-shoot transport. In metal hyperaccumulators, however, greatly reduced VSC in roots has evolved, which greatly promotes long-distance metal 
transport from roots to shoots. We also reviewed the regulation mechanisms of VSC by tonoplast-localized transporters and ion chelators. we believe that the study of VSC would contribute not only to a better understanding of metal homeostasis and distribution, but also to an efficient biofortification of essential mineral nutrients and phytoremediation of non-essential toxic metals.

As a primary producer, plants provide a lot of mineral nutrients that are essential for human health. However, some of these nutrients in the edible parts of stable crops are often deficient or poorly bioavailable thus resulting in an unbalanced diet. Therefore, nutrient biofortification is of urgent and necessary importance. In addition to the traditional approaches that tackle these concerns by increasing the efficiency of nutrient uptake and bioavailability (reviewed by Hirschi, 2009), modulation of VSC might be a more efficient way, in which nutrient taken into plants are forced to accumulate in targeted tissues, thus enhanced uptake might not be required and the risk of undesired accumulation of toxic metals is greatly reduced (Arrivault et al., 2006; Haydon et al., 2012; Zhang et al., 2012). Furthermore, targeted modulation of VSC could also help to reduce toxic metal accumulation in edible tissues, as demonstrated by the root-specific expression of SpHMT1 or the natural variation in OsHMA3 in rice (Ueno et al., 2010; Huang et al., 2012), where a strong correlation between the VSC in roots and metal accumulation in shoots was observed.

On the other side, phytoremediation has been proposed as an efficient way to tackle the widespread heavy metal pollution in many countries, however, the practical application of metal hyperaccumulators to field trial is not so optimistic, mainly because of the relative low biomass and growth rate of those specialized plants. In these specific circumstances, an optimal alternative could be the fine modulation of the VSC in both roots and shoots in some plants with large biomass and growth rate.

\section{REFERENCES}

Arrivault, S., Senger, T., and Krämer, U. (2006). The Arabidopsis metal tolerance protein AtMTP3 maintains metal homeostasis by mediating $\mathrm{Zn}$ exclusion from the shoot under Fe deficiency and Zn oversupply. Plant J. 46, 861-879. doi: 10.1111/j.1365-313X.2006.02746.x

Assunção, A. G. L., Martins, P. D., De Folter, S., Vooijs, R., Schat, H., and Aarts, M. G. M. (2001). Elevated expression of metal transporter genes in three accessions of the metal hyperaccumulator Thlaspi caerulescens. Plant Cell Environ. 24, 217-226. doi: 10.1111/j.1365-3040.2001.00666.x

Becher, M., Talke, I. N., Krall, L., and Krämer, U. (2004). Crossspecies microarray transcript profiling reveals high constitutive expression of metal homeostasis genes in shoots of the zinc hyperaccumulator Arabidopsis halleri. Plant J. 37, 251-268. doi: 10.1046/j.1365-313X.2003. 01959.x

Cobbett, C. S., and Goldsbrough, P. (2002). Phytochelatins and metallothioneins: roles in heavy metal detoxification and homeostasis. Annu. Rev. Plant Biol. 53, 159-182. doi: 10.1146/annurev.arplant.53.100301.135154

Curie, C., Cassin, G., Couch, D., Divol, F., Higuchi, K., Le Jean, M., et al. (2009). Metal movement within the plant: contribution of nicotianamine and yellow stripe 1-like transporters. Ann. Bot. 103, 1-11. doi: 10.1093/aob/ $\operatorname{mcn} 207$

Deinlein, U., Weber, M., Schmidt, H., Rensch, S., Trampczynska, A., Hansen, T. H., et al. (2012). Elevated nicotianamine levels in Arabidopsis halleri roots play a key role in zinc hyperaccumulation. Plant Cell 24, 708-723. doi: 10.1105/tpc. 111.095000
Desbrosses-Fonrouge, A. G., Voigt, K., Schröder, A., Arrivault, S., Thomine, S., and Krämer, U. (2005). Arabidopsis thaliana MTP1 is a $\mathrm{Zn}$ transporter in the vacuolar membrane which mediates $\mathrm{Zn}$ detoxification and drives leaf $\mathrm{Zn}$ accumulation. FEBS Lett. 579, 4165-4174. doi: 10.1016/j.febslet.2005.06.046

Dräger, D. B., Desbrosses-Fonrouge, A. G., Krach, C., Chardonnens, A. N., Meyer, R. C., Saumitou-Laprade, P., et al. (2004). Two genes encoding Arabidopsis halleri MTP1 metal transport proteins co-segregate with zinc tolerance and account for high MTP1 transcript levels. Plant J. 39, 425-439. doi: 10.1111/j.1365-313X.2004.02143.x

Garcia-Molina, A., Andrés-Colás, N., Perea-García, A., Del Valle-Tascón, S., Peñarrubia, L., and Puig, S. (2011). The intracellular Arabidopsis COPT5 transport protein is required for photosynthetic electron transport under severe copper deficiency. Plant J. 65, 848-860. doi: 10.1111/j.1365-313X.2010.04472.x

Gong, J. M., Lee, D. A., and Schroeder, J. I. (2003). Long-distance root-to-shoot transport of phytochelatins and cadmium in Arabidopsis. Proc. Natl. Acad. Sci. U.S.A. 100, 10118-10123. doi: 10.1073/pnas.1734072100

Gustin, J. L., Loureiro, M. E., Kim, D., Na, G., Tikhonova, M., and Salt, D. E. (2009). MTP1-dependent Zn sequestration into shoot vacuoles suggests dual roles in $\mathrm{Zn}$ tolerance and accumulation in $\mathrm{Zn}$-hyperaccumulating plants. Plant J. 57, 1116-1127. doi: 10.1111/j.1365-313X.2008.03754.x

Hammond, J. P., Bowen, H. C., White, P. J., Mills, V., Pyke, K. A., Baker, A. J., et al. (2006). A comparison of the Thlaspi caerulescens and Thlaspi arvense shoot transcriptomes. New Phytol. 170, 239-260. doi: 10.1111/j.1469-8137.2006. 01662.x

Haydon, M. J., and Cobbett, C. S. (2007). A novel major facilitator superfamily protein at the tonoplast influences zinc tolerance and accumulation in Arabidopsis. Plant Physiol. 143, 1705-1719. doi: 10.1104/pp.106.092015

Haydon, M. J., Kawachi, M., Wirtz, M., Hillmer, S., Hell, R., and Krämer, U. (2012). Vacuolar nicotianamine has critical and distinct roles under iron deficiency and for zinc sequestration in Arabidopsis. Plant Cell 24, 724-737. doi: 10.1105/tpc.111.095042

Hirschi, K. D. (2009). Nutrient biofortification of food crops. Annu. Rev. Nutr. 29, 401-421. doi: 10.1146/annurev-nutr-080508-141143

Huang, J., Zhang, Y., Peng, J. S., Zhong, C., Yi, H. Y., Ow, D. W., et al. (2012). Fission yeast HMT1 lowers seed cadmium through phytochelatin-dependent vacuolar sequestration in Arabidopsis. Plant Physiol. 158, 1779-1788. doi: 10.1104/pp.111.192872

Kawachi, M., Kobae, Y., Mori, H., Tomioka, R., Lee, Y., and Maeshima, M. (2009). A mutant strain Arabidopsis thaliana that lacks vacuolar membrane zinc transporter MTP1 revealed the latent tolerance to excessive zinc. Plant Cell Physiol. 50, 11561170. doi: 10.1093/pcp/pcp067

Kerkeb, L., and Krämer, U. (2003). The role of free histidine in xylem loading of nickel in Alyssum lesbiacum and Brassica juncea. Plant Physiol. 131, 716-724. doi: 10.1104/pp102.010686

Kim, S. A., Punshon, T., Lanzirotti, A., Li, L., Alonso, J. M., Ecker, J. R., et al. (2006). Localization of iron in Arabidopsis seed requires the vacuolar membrane transporter VIT1. Science 314, 1295-1298. doi: 10.1126/science.1132563

Klaumann, S., Nickolaus, S. D., Fürst, S. H., Starck, S., Schneider, S., Ekkehard Neuhaus, H., etal. (2011). The tonoplast copper transporter COPT5 acts as an exporter and is required for interorgan allocation of copper in Arabidopsis thaliana. New Phytol. 192, 393-404. doi: 10.1111/j.1469-8137.2011. 03798.x

Kobae, Y., Uemura, T., Sato, M. H., Ohnishi, M., Mimura, T., Nakagawa, T., et al. (2004). Zinc transporter of Arabidopsis thaliana AtMTP1 is localized to vacuolar membranes and implicated in zinc homeostasis. Plant Cell Physiol. 45, 1749-1758. doi: $10.1093 / \mathrm{pcp} / \mathrm{pci0} 15$

Korenkov, V., Hirschi, K., Crutchfield, J. D., and Wagner, G. J. (2007). Enhancing tonoplast $\mathrm{Cd} / \mathrm{H}$ antiport activity increases $\mathrm{Cd}, \mathrm{Zn}$, and $\mathrm{Mn}$ tolerance, and impacts root/shoot Cd partitioning in Nicotiana tabacum L. Planta 226, 1379-1387. doi: 10.1007/s00425-007-0577-0

Krämer, U. (2010). Metal hyperaccumulation in plants. Annu. Rev. Plant Biol. 61, 517-534. doi: 10.1146/annurev-arplant-042809-112156

Krämer, U., Cotter-Howells, J. D., Charnock, J. M., Baker, A. J. M., and Smith, J. A. C. (1996). Free histidine as a metal chelator in plants that accumulate nickel. Nature 379, 635-638. doi: 10.1038/379635a0

Krämer, U., Pickering, I. J., Prince, R. C., Raskin, I., and Salt, D. E. (2000). Subcellular localization and speciation of nickel in hyperaccumulator and non-accumulator Thlaspi species. Plant Physiol. 122, 1343-1353. doi: 10.1104/pp.122.4.1343 
Küpper, H., Lombi, E., Zhao, F. J., Wieshammer, G., and McGrath S. P. (2001). Cellular compartmentation of nickel in the hyperaccumulators Alyssum lesbiacum, Alyssum bertolonii and Thlaspi goesingense. J. Exp. Bot. 52, 2291-2300. doi: 10.1093/jexbot/52.365.2291

Küpper, H., Zhao, F. J., and McGrath S. P. (1999). Cellular compartmentation of zinc in leaves of the hyperaccumulator Thlaspi caerulescens. Plant Physiol. 119 305-312. doi: 10.1104/pp.119.1.305

Lanquar, V., Lelièvre, F., Bolte, S., Hamès, C., Alcon, C., Neumann, D., et al. (2005). Mobilization of vacuolar iron by AtNRAMP3 and AtNRAMP4 is essential for seed germination on low iron. EMBO J. 24, 4041-4051. doi: 10.1038/sj.emboj. 7600864

Lasat, M. M., Baker, A. J., and Kochian, L. V. (1998). Altered Zn compartmentation in the root symplasm and stimulated $\mathrm{Zn}$ absorption into the leaf as mechanisms involved in Zn hyperaccumulation in Thlaspi caerulescens. Plant Physiol. 118, 875-883. doi: 10.1104/pp.118.3.875

Ma, J. F., Ueno, D., Zhao, F. J., and McGrath S. P. (2005). Subcellular localisation of $\mathrm{Cd}$ and $\mathrm{Zn}$ in the leaves of a Cd-hyperaccumulating ecotype of Thlasp caerulescens. Planta 220, 731-736. doi: 10.1007/s00425-004-1392-5

Martinoia, E., Meyer, S., De Angeli, A., and Nagy, R. (2012). Vacuolar transporters in their physiological context. Annu. Rev. Plant Biol. 63, 183-213. doi: 10.1146/annurev-arplant-042811-105608

Mei, H., Cheng, N. H., Zhao, J., Park, S., Escareno, R. A., Pittman, J. K., et al. (2009). Root development under metal stress in Arabidopsis thaliana requires the H+/cation antiporter CAX4. New Phytol. 183, 95-105. doi: 10.1111/j.14698137.2009.02831.x

Mendoza-Cozatl, D. G., Jobe, T. O., Hauser, F., and Schroeder, J. I. (2011). Long-distance transport, vacuolar sequestration, tolerance, and transcriptional responses induced by cadmiumand arsenic. Curr. Opin. Plant Biol. 14, 554-562. doi: 10.1016/j.pbi.2011.07.004

Morrissey, J., Baxter, I. R., Lee, J., Li, L., Lahner, B., Grotz, N., et al. (2009), The ferroportin metal efflux proteins function in iron and cobalt homeostasis in Arabidopsis. Plant Cell. 21, 3326-3338. doi: 10.1105/tpc.109. 069401

Persans, M. W., Nieman, K., and Salt, D. E. (2001). Functional activity and role of cation-efflux family members in $\mathrm{Ni}$ hyperaccumulation in Thlaspi goesingense. Proc. Natl. Acad. Sci. U.S.A. 98, 9995-10000. doi: 10.1073/pnas. 171039798

Ricachenevsky, F. K., Menguer, P. K., Sperotto, R. A., Williams, L. E., and Fett, J. P. (2013). Roles of plant metal tolerance proteins (MTP) in metal storage and potential use in biofortification strategies. Front. Plant Sci. 4:144. doi: 10.3389/fpls.2013.00144

Richau, K. H., Kozhevnikova, A. D., Seregin, I. V., Vooijs, R., Koevoets, P. L., Smith, J. A., et al. (2009). Chelation by histidine inhibits the vacuolar sequestration of nickel in roots of the hyperaccumulator Thlaspi caerulescens. New Phytol. 183, 106-116. doi: 10.1111/j.1469-8137.2009.02826.x

Schaaf, G., Honsbein, A., Meda, A. R., Kirchner, S., Wipf, D., and von Wirén, N. (2006). AtIREG2 encodes a tonoplast transport protein involved in irondependent nickel detoxification in Arabidopsis thaliana roots. J. Biol. Chem. 281, 25532-25540. doi: 10.1074/jbc.M601062200

Shahzad, Z., Gosti, F., Frérot, H., Lacombe, E., Roosens, N., Saumitou-Laprade, P., et al. (2010). The five AhMTP1 zinc transporters undergo different evolutionary fates towards adaptive evolution to zinc tolerance in Arabidopsis halleri. PLoS Genet. 6:e1000911. doi: 10.1371/journal.pgen.1000911

Sinclair, S. A., and Krämer, U. (2012). The zinc homeostasis network of land plants. Biochim. Biophys. Acta. 1823, 1553-1567. doi: 10.1016/j.bbamcr.2012. 05.016
Talke, I. N., Hanikenne, M., and Krämer, U. (2006). Zinc-dependent global transcriptional control, transcriptional deregulation, and higher gene copy number for genes in metal homeostasis of the hyperaccumulator Arabidopsis halleri. Plant Physiol. 142, 148-167. doi: 10.1104/pp.105.076232

Thomine, S., Lelièvre, F., Debarbieux, E., Schroeder, J. I., and Barbier-Brygoo, H. (2003). AtNRAMP3, a multispecific vacuolar metal transporter involved in plant responses to iron deficiency. Plant J. 34, 685-695. doi: 10.1046/j.1365313X.2003.01760.X

Thomine, S., Wang, R., Ward, J. M., Crawford, N. M., and Schroeder, J. I. (2000). Cadmium and iron transport by members of a plant metal transporter family in Arabidopsis with homology to Nramp genes. Proc. Natl. Acad. Sci. U.S.A. 97, 991-996. doi: 10.1073/pnas.97.9.4991

Ueno, D., Milner, M. J., Yamaji, N., Yokosho, K., Koyama, E., Clemencia Zambrano, M., et al. (2011). Elevated expression of TcHMA3 plays a key role in the extreme Cd tolerance in a Cd-hyperaccumulating ecotype of Thlaspi caerulescens. Plant J. 66, 852-862. doi: 10.1111/j.1365-313X.2011.04548.x

Ueno, D., Yamaji, N., Kono, I., Huang, C. F., Ando, T., Yano, M., et al. (2010). Gene limiting cadmium accumulation in rice. Proc. Natl. Acad. Sci. U.S.A. 107, 16500-16205. doi: 10.1073/pnas.1005396107

van de Mortel, J. E., Almar Villanueva, L., Schat, H., Kwekkeboom, J., Coughlan, S., Moerland, P. D., et al. (2006). Large expression differences in genes for iron and zinc homeostasis, stress response, and lignin biosynthesis distinguish roots of Arabidopsis thaliana and the related metal hyperaccumulator Thlaspi caerulescens. Plant Physiol. 142, 1127-1147. doi: 10.1104/pp.106.082073

Xing, J. P., Jiang, R. F., Ueno, D., Ma, J. F., Schat, H., McGrath S. P., et al. (2008). Variation in root-to-shoot translocation of cadmium and zinc among different accessions of the hyperaccumulators Thlaspi caerulescens and Thlaspi praecox. New Phytol. 178, 315-325. doi: 10.1111/j.1469-8137.2008.02376.x

Yang, X. E., Li, T. Q., Long, X. X., Xiong, X. H., He, Z. H., and Stoffella, P. J. (2006). Dynamics of zinc uptake and accumulation in the hyperaccumulating and non-hyperaccumulating ecotypes of Sedum alfredii Hance. Plant and Soil. 284,109-119. doi: 10.1007/s11104-006-0033-0

Zhang, M., Senoura, T., Yang, X., and Nishizawa, N. K. (2011). Functional analysis of metal tolerance proteins isolated from $\mathrm{Zn} / \mathrm{Cd}$ hyperaccumulating ecotype and non-hyperaccumulating ecotype of Sedum alfredii Hance. FEBS Lett. 585, 26042609. doi: 10.1016/j.febslet.2011.07.013

Zhang, Y., Xu, Y. H., Yi, H. Y., and Gong, J. M. (2012). Vacuolar membrane transporters OsVIT1 and OsVIT2 modulate iron translocation between flag leaves and seeds in rice. Plant J. 72, 400-410. doi: 10.1111/j.1365-313X.2012.05088.x

Conflict of Interest Statement: The authors declare that the research was conducted in the absence of any commercial or financial relationships that could be construed as a potential conflict of interest.

Received: 04 December 2013; accepted: 15 January 2014; published online: 04 February 2014.

Citation: Peng J-S and Gong J-M (2014) Vacuolar sequestration capacity and longdistance metal transport in plants. Front. Plant Sci. 5:19. doi: 10.3389/fpls.2014.00019 This article was submitted to Plant Nutrition, a section of the journal Frontiers in Plant Science.

Copyright (@) 2014 Peng and Gong. This is an open-access article distributed under the terms of the Creative Commons Attribution License (CC BY). The use, distribution or reproduction in other forums is permitted, provided the original author(s) or licensor are credited and that the original publication in this journal is cited, in accordance with accepted academic practice. No use, distribution or reproduction is permitted which does not comply with these terms. 